\title{
KENDALI KECEPATAN MOTOR POMPA AIR DC MENGGUNAKAN PID - CSA BERDASARKAN DEBIT AIR BERBASIS ARDUINO
}

\author{
Alfrino Andreas ${ }^{1}$, Gigih Priyandoko ${ }^{2}$, Mohammad Mukhsim ${ }^{3}$ \\ 1,2,3 Teknik Elektro, Universitas Widyagama \\ Email: frinoandreas@yahoo.com
}

\begin{abstract}
Abstrak
Pompa air menghasilkan tekanan yang dibutuhkan cairan untuk mengatasi gravitasi, gesekan maupun tekanan sistem sehingga air dapat dialirkan bahkan dari tempat bertekanan rendah ke tempat bertekanan tinggi. Debit/aliran air menjadi salah satu parameter penting yang selalu menjadi perhatian penggunanya. Ada beberapa sistem yang kerjanya dipengaruhi oleh aliran air seperti sirkulasi pada akuarium. Pada sistem sirkuasi akuarium yang besar atau banyak perlu pengaturan aliran yang seimbang, jika terdapat aliran yang berubah-ubah, sirkulasi air pada akuarium menjadi tidak stabil. Aliran air harus dipertahankan konstan agar hal tersebut tidak terjadi. Untuk mempertahankan aliran air pompa ketika keran dibuka atau ditutup, penulis menggunakan kontrol kecepatan motor dengan kontrol PID dengan optimasi Cucko Search Algorithm sebagai optimasi dalam mencari nilai Kp, $K i$, dan Kd. Kecepatan motor pompa dikendalikan dengan driver PWM dengan kontrol berbasis pada arduino uno.
\end{abstract}

Kata kunci: Pompa air, PID, Cucko Search Algorithm.

\begin{abstract}
The water pump produces pressure that is needed by the liquid to overcome gravity, friction and system pressure so that water can be flowed even from a low pressure place to a high pressure place. Water discharge/flow is one of the important parameters that are always of concern to users. There are several systems whose work is affected by water flow such as circulation in the aquarium. In large or many aquarium circuits, a balanced flow arrangement is needed, if there is a fluctuating flow, the water circulation in the aquarium becomes unstable. Water flow must be kept constant so that this does not occur. To maintain the pump water flow when the tap is opened or closed, the author uses motor speed control with PID control with Cucko Search Algorithm optimization as an optimization in finding the values of Kp, $K i$, and Kd. The speed of the pump motor is controlled by the PWM driver with control based on Arduino uno.
\end{abstract}

Keywords: Water pump, PID, Cucko Search Algorithm. 


\section{PENDAHULUAN}

Beberapa penelitian sebelumnya menguraikan pembahasan tentang pengaturan kecepatan pompa air dengan menggunakan variable speed drive (VSD) [1] dan dikontrol dengan mikrokontroler Arduino [2]. Namun terdapat beberapa kelemahan yaitu pada sistem kontrol dimana tidak ada kontrol untuk mengoptimasi kontroller tersebut, sehingga putaran yang dihasilkan untuk mempertahankan debit air pompa tidak efisien dan stabil. Untuk itulah penulis mengangkat kembali dengan memperbaiki sistem kontrol dengan menggunakan kontrol PID berbasis arduino dengan pengoptimalan menggunakan kecerdasan buatan yaitu Cuckoo Search Algorithm (CSA).

Penelitian ini menggunakan pompa air DC sebagai alat untuk mensimulasikan pengendalian kecepatan motor pompa dengan kontrol PID dengan optimasi CSA berdasarkan debit air keluaran motor. Agar debit/aliran dapat dipertahankan konstan berapa-pun valve/keran yang dibuka, dilakukan pengaturan kecepatan pompa dengan kontrol PID [3]. Kontrol tersebut secara otomatis merubah nilai tegangan dalam menambah kecepatan motor ketika debit air berkurang dan mengurangi kecepatan motor pompa ketika debit air bertambah. Keunggulan pengendali PID adalah mudah untuk diterapkan dan berbiaya rendah. Akan tetapi, penggunaan kontroler PID dibutuhkan pengaturan parameter yang tepat untuk mendapatkan kinerja yang optimal pada motor. Umumnya yang sering digunakan adalah metode trial-error, untuk menentukan parameter yang tepat untuk PID, namun hasil yang didapat tidak membuat kontroler PID optimal. Belakangan ini sudah banyak penelitian untuk mengoptimasi kontroler PID, salah satunya dengan metode kecerdasan buatan. Untuk itu pada penelitian ini akan digunakan metode cerdas berbasis Cuckoo Search Algorithm (CSA), untuk mengoptimasi dan menentukan parameter yang tepat dari PID. CSA adalah salah satu metode cerdas yang terinspirasi dari perilaku burung cuckoo dalam menempatkan telurnya disarang burung lain yang dia pilih secara acak, konsep inilah yang diadaptasi dan diterapkan menjadi algoritma cerdas untuk menyelesaikan masalah optimasi. Dari hasil yang diperoleh metode CSA dapat dengan baik menala parameter PID, sehingga overshoot yang dihasilkan tidak ada dan settling time sangat cepat [4].

Metode CSA disebutkan lebih baik dari beberapa metode sebelumnya seperti PSO [5], dan GA baik itu dilihat dari sisi ketepatan dan juga kecepatan dalam penyelesaian masalah. Selain itu keunggulan dari Cuckoo Search ini sendiri terletak pada random stepnya yang menggunakan Lévy Flights (konsep pencarian makanan secara random pada hewan ketika sedang terbang), yang memungkinkan pencarian nilai optimal dalam waktu yang lebih singkat [6].

\section{STUDI PUSTAKA}

\subsection{Motor DC}

Motor DC adalah motor listrik yang memerlukan suplai tegangan arus searah pada kumparan medan untuk diubah menjadi energi gerak mekanik. Kumparan medan pada Motor DC disebut stator (bagian yang tidak berputar) dan kumparan jangkar disebut rotor (bagian yang berputar). Motor arus searah, sebagaimana namanya, menggunakan arus langsung yang tidak langsung/directunidirectional. Motor DC memiliki 3 bagian atau komponen utama untuk dapat 
berputar sebagai berikut [7]. Kutub medan. Motor DC sederhana memiliki dua kutub medan: kutub utara dan kutub selatan. Garis magnetik energi membesar melintasi ruang terbuka diantara kutub-kutub dari utara ke selatan. Untuk motor yang lebih besar atau lebih komplek terdapat satu atau lebih elektromagnet. Current Elektromagnet atau Dinamo. Dinamo yang berbentuk silinder, dihubungkan ke as penggerak untuk menggerakan beban. Untuk kasus motor DC yang kecil, dinamo berputar dalam medan magnet yang dibentuk oleh kutubkutub, sampai kutub utara dan selatan magnet berganti lokasi. Commutator. Komponen ini terutama ditemukan dalam motor DC. Kegunaannya adalah untuk transmisi arus antara dinamo dan sumber daya.

Jika arus lewat pada suatu konduktor, timbul medan magnet di sekitar konduktor. Arah medan magnet ditentukan oleh arah aliran arus pada konduktor. Untuk menentukan arah putaran motor digunakan faedah Flamming tangan kiri. Kutub-kutub magnet akan menghasilkan medan magnet dengan arah dari kutub utara ke kutub selatan. Jika medan magnet memotong sebuah kawat penghantar yang dialiri arus searah dengan empat jari, maka akan timbul gerak searah ibu jari. Gaya ini disebut gaya Lorentz, yang besarnya sama dengan F. Prinsip motor : aliran arus di dalam penghantar yang berada di dalam pengaruh medan magnet akan menghasilkan gerakan. Besarnya gaya pada penghantar akan bertambah besar jika arus yang melalui penghantar bertambah besar.

\subsection{Kontrol PID}

Kontrol PID adalah salah satu kontrol yang sudah banyak digunakan pada aplikasi industri karena strukturnya yang sederhana.

$$
m v(t)=k p e(t)+\frac{k p}{t i} \int_{0}^{t} e(t) d t+k_{p} T_{d} \frac{d e(t)}{d t}
$$

Di mana, $\mathrm{m}(\mathrm{t})$ adalah nilai kontrol yang dihitung oleh kontroler PID, Kp adalah koefisien proporsional, Ti adalah integral waktu konstan dan Td adalah diferensian time konstan. Fungsi dari ketiga elemen tersebut adalah :

a. Proporsional: menggambarkan sinyal deviasie (t) dari sistem kontrol proporsional. Ketika sinyal e(t) ada, kontroler PID menghasilkan efek kontrol segera untuk mengurangi penyimpangan.

b. Integral : digunakan untuk menghilangkan kesalahan statis dan meningkatkan stabilitas sistem.

c. Diferensial: mencerminkan perubahan penyimpangansinyal, memperkenalkan sinyal koreksi sebelum penyimpangannilai sinyal menjadi lebih besar dan mempercepat responsistem untuk mengurangi pengaturan waktu.

Oleh karena itu, merancang kontroler PID terutama berarti menentukan tiga parameter, serta bagaimana mengkonfigurasi ke tiga parameter PID (Kp, Ki, Kd). Dalam penelitian ini, Cuckoo SearchAlgorithm diusulkan untuk mencari parameter optimal PID.Blok diagram sistem kontrol ditunjukkan pada gambar 1. 


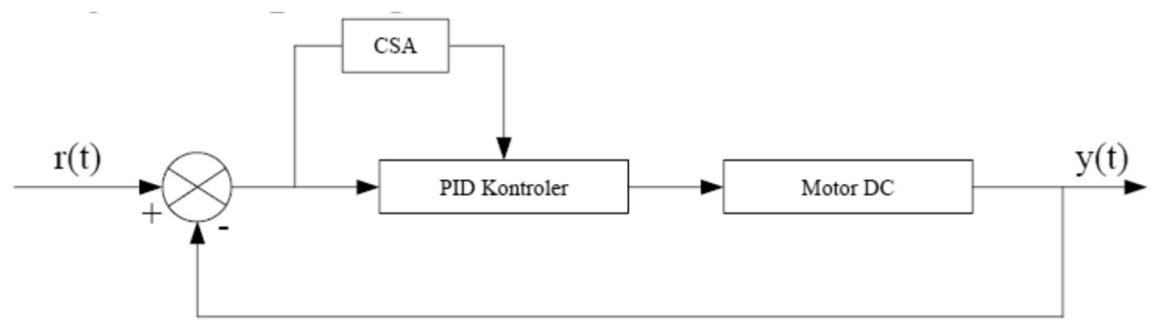

Gambar 1. Sistem kontrol PID-CSA [4]

\subsection{Cuckoo Search Alogaritma (CSA)}

CSA adalah salah satu metode cerdas yang terinspirasi dari perilaku burung cuckoo dalam menempatkan telurnya disarang burung lain yang dia pilih secara acak, konsep inilah yang diadaptasi dan diterapkan menjadi algoritma cerdas untuk menyelesaikan masalah optimasi [6]. Dari beberapa jurnal yang diperoleh metode CSA dapat dengan baik menala parameter PID dibanding dengan metode lain karena overshoot yang dihasilkan mendekati nol atau tidak ada dan settling time sangat cepat [4], [8].

Burung cuckoo dalam berkembang biak memiliki cara yang beragam dan unik. Dari sekian spesies cuckoo diketahui bahwa 59 diantaranya merupakan cuckoo yang bersifat parasit dalam berkembang biak yaitu mereka memanfaatkan sarang burung lain yang berbeda spesies untuk menetaskan telur mereka. Bahkan tak jarang burung cuckoo yang menaruh telur pada sarang burung cuckoo yang lain. Ada beberapa jenis cuckoo yang membuang telur dari induk asli pada sarang untuk meningkatan kemungkinan menetas telur mereka. Mungkin saja terjadi konflik antara burung host dan burung cuckoo pada saat burung cuckoo menaruh telurnya, sehingga burung host membuang telur cuckoo tersebut atau meninggalkan sarang mereka kemudian membuang sarang yang baru. Setiap cuckoo meletakkan satu telur pada satu waktu dan membuang telur didalamnya pada sarang yang dipilih acak. Sarang terbaik dengan kualitas telur tertinggi akan dilanjutkan ke generasi berikutnya [4].

Cuckoo Search didasarkan pada tiga aturan ideal, yaitu :

1. Setiap cuckoo meletakkan satu telur pada satu waktu, dan membuang telurnya di sarang yang dipilih secara acak

2. Sarang terbaik dengan kualitas telur yang tinggi akan terbawa ke generasi berikutnya

3. Jumlah sarang burung tuan rumah yang tersedia bersifat tetap, probabilitas telur yang telah diletakkan oleh burung Kukuk (Cuckoo) dan ditemukan oleh burung tuan rumah dijabarkan dengan pa $\epsilon[0,1]$. Dalam kasus ini burung tuan rumah dapat membuang telur tersebut atau meninggalkan sarang dan membangun sarang di tepat yang baru.

Berdasarkan tiga aturan tersebut, langkah - langkah dasar Cuckoo Search (CS) dapat diringkas sebagai persamaan berikut

$$
x i(t+1)=x i(t)+\alpha \oplus L^{\prime} e v y(\lambda)
$$


Dimana xi $(\mathrm{t}+1)$ adalah generasi solusi baru, i adalah burng kukuk ke-i. $a>0$ adalah ukuran langkah yang seharusnya berhubungan dengan skala kepentingan masalah tersebut. Dalam kebanyakan kasus dapat digunakan $\mathrm{a}=\mathrm{O}$ (L/10), L adalah karakteristik skala kepentingan masalah [7], Sedangkan Lévy( $(\lambda)$ menyatakan fungsi persamaan posisi dari Lévy Flights yang bentuk persamaannya adalah sebagai berikut.

$$
\text { L'evy } \sim \mathrm{u}=\mathrm{t}-\lambda,(1<\lambda \leq 3)
$$

Persamaan 2 merupakan persamaan stokastik untuk langkah acak (random walk). Secara umum, langkah acak (random walk) adalah rantai Markov yang status / lokasi berikutnya hanya tergantung pada lokasi saat ini dan probabilitas transisi. Lambang $\oplus$ berarti perkalian entrywise [7]. berikut

Pseudocode dari Cuckoo Search Algorithm (CSA) dapat dijabarkan sebagai

Tabel 1. Pseudo code dari Cuckoo Search (CS)

Begin
Fungsi Objektif $f(x), x=\left(x_{1}, \ldots, x d\right)^{T}$
Inisialisasi populasi dari $n$ sarang burung target $x i(i=1,2, \ldots, n)$ While ( $t<$ generasiTotal)
atau (kriteria lain untuk berhenti) Evaluasi nilai kualitas dari masing-masing burung
cuckoo Pilih dari burung cuckoo secara acak dan lakukan random walk
Jika (Fi> Fj)
Gantikan burung cuckoo j dengan burung cuckoo i
End If
$\quad$ Reset ulang sarang-sarang dengan kondisi terburuk (Pa) Simpan sarang-sarang
yang berhasil lolos
Urutkan solusi dan cari yang terbaik
End While
Proses hasil dan visualisasi
End

\subsection{Penalaan PID dengan CSA}

Parameter PID yang ditala oleh CSA adalah Kp, Ki dan Kd. Adapun untuk diagram alir proses penalaan parameter PID dengan menggunakan metode Cuckoo Search Algorithm (CSA) ditunjukkan oleh flowchart pada Gambar berikut 


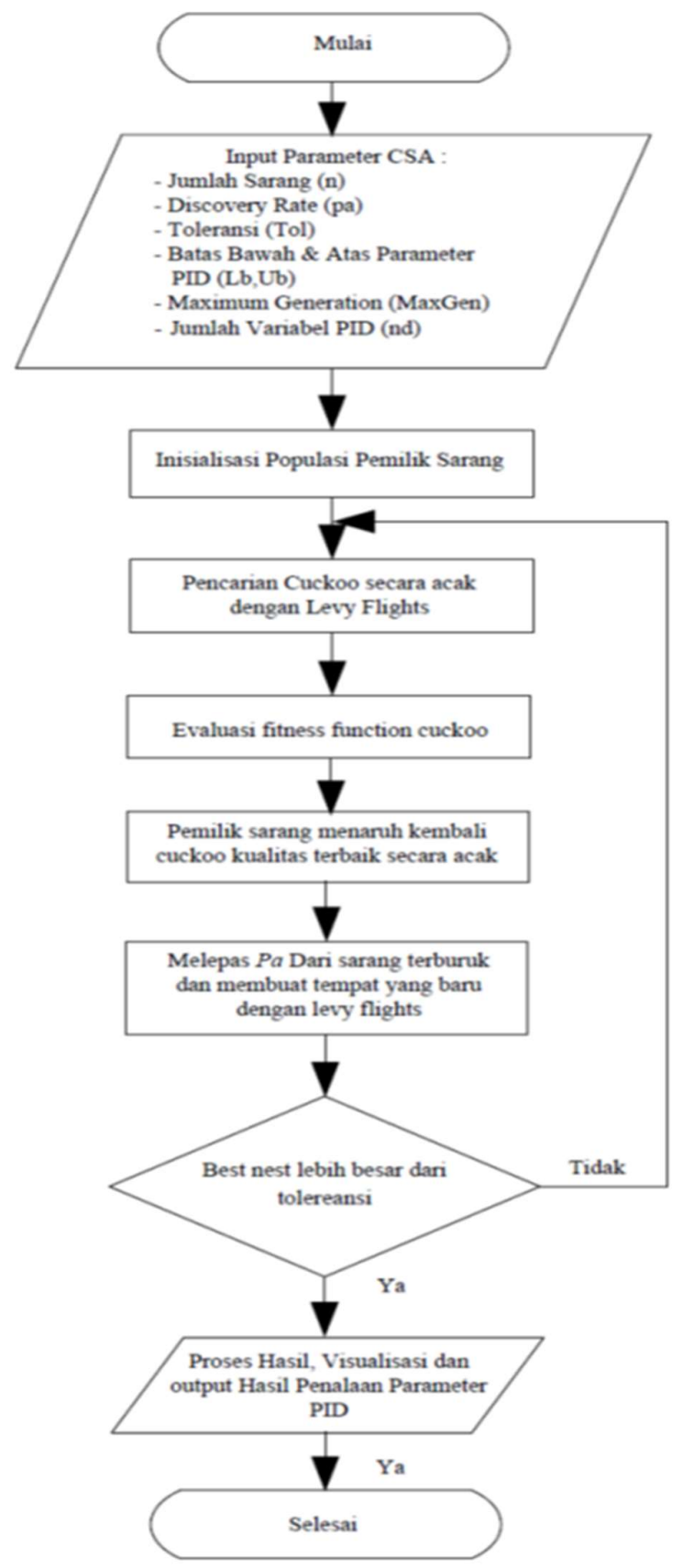

Gambar 2. Flow chart metode Cuckoo Search Algorithm [4]

\subsection{PWM (Pulse Widh Modulation Alogaritma)}

PWM ( Pulse Width Modulation) adalah salah satu teknik modulasi dengan mengubah lebar pulsa (duty cylce) dengan nilai amplitudo dan frekuensi yang tetap. Satu siklus pulsa merupakan kondisi high kemudian berada di zona transisi ke kondisi low.Lebar pulsa PWM berbanding lurus dengan amplitudo sinyal asli yang belum termodulasi. Duty Cycle merupakan representasi dari kondisi logika high dalam suatu periode sinyal dan di nyatakan dalam bentuk (\%) dengan range 0\% sampai $100 \%$, sebagai contoh jika sinyal berada dalam kondisi high terus 
menerus artinya memiliki duty cycle sebesar 100\%. Jika waktu sinyal keadaan high sama dengan keadaan low maka sinyal mempunyai duty cycle sebesar $50 \%$ [7].

PWM pada arduino UNO bekerja pada frekuensi $500 \mathrm{~Hz}$, artinya 500 siklus/ketukan dalam satu detik. Untuk setiap siklus, kita bisa memberi nilai dari 0 hingga 255. Ketika kita memberikan angka 0 , berarti pada pin tersebut akan pernah bernilai 0 volt atau setara dengan GND. Sedangkan jika kita memberikan nilai 255, maka sepanjang siklus akan bernilai 5 volt [9].

Kondisi HIGH adalah kondisi ketika sinyal berada di atas grafik (5V) dan LOW adalah ketika sinyal berada di bawah (OV). Duty cycle adalah persentasi panjang pulsa HIGH dalam satu periode sinyal. Ketika duty cyclenya $0 \%$ atau sinyal LOW penuh, maka nilai analog yang dikeluarkan adalah OV atau setara dengan GND. Ketika duty cyclenya $100 \%$ atau sinyal $\mathrm{HIGH}$ penuh maka sinyal yang dikeluarkan adalah $5 \mathrm{~V}$.

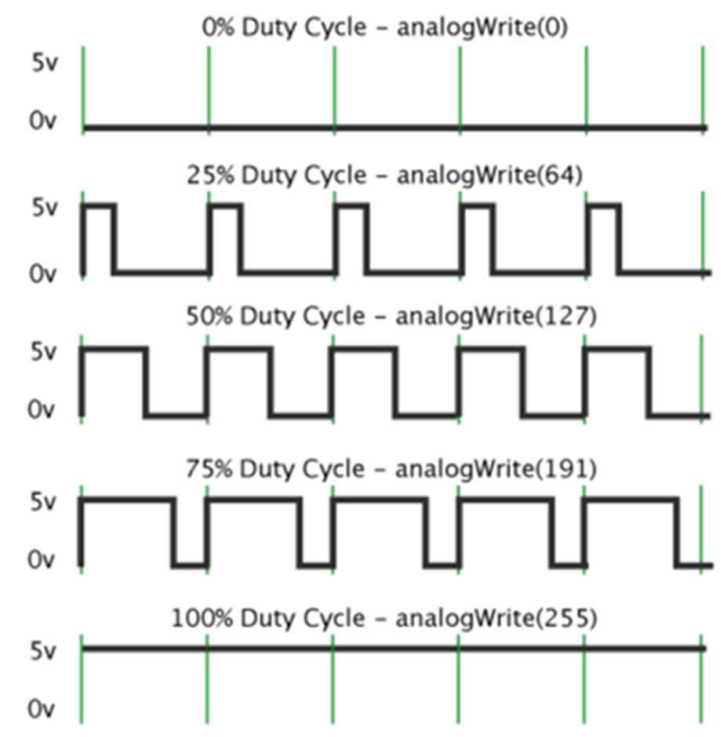

Gambar 3. Flow chart metode Cuckoo Search Algorithm [9]

Untuk mengatur nilai duty cycle, kita gunakan fungsi analogWrite([nomorPin], [nilai]). Nilai pada parameter berkisar antara 0 hingga 255. Bila kita hendak mengeset duty cycle ke 0\%, maka kita set nilai parameter ke 0 , dan untuk duty cycle 100\%, maka kita set nilai parameter ke 255. Jadi bila misalkan kita hendak mengeset duty cycle ke 50\%, berarti nilai yang harus kita set adalah 127 (50\% x 255).

Sebenarnya berdasarkan konsep PWM di atas, kita dapat mensimulasikan PWM pada semua pin digital. Tapi khusus penggunaan fungsi digitalWrite() kita hanya bisa menggunakannya pada pin-pin PWM. Seperti pada Arduino Uno, pin yang dapat menggunakan fungsi ini hanya pin 3, 5, 6, 9, 10 dan 11 . Biasanya pin PWM disimbolkan dengan karakter ' ' [10]. 


\section{METODE}

Dalam metode penelitian ini akan digambarkan dengan blok diagram penelitian secara keseluruhan.
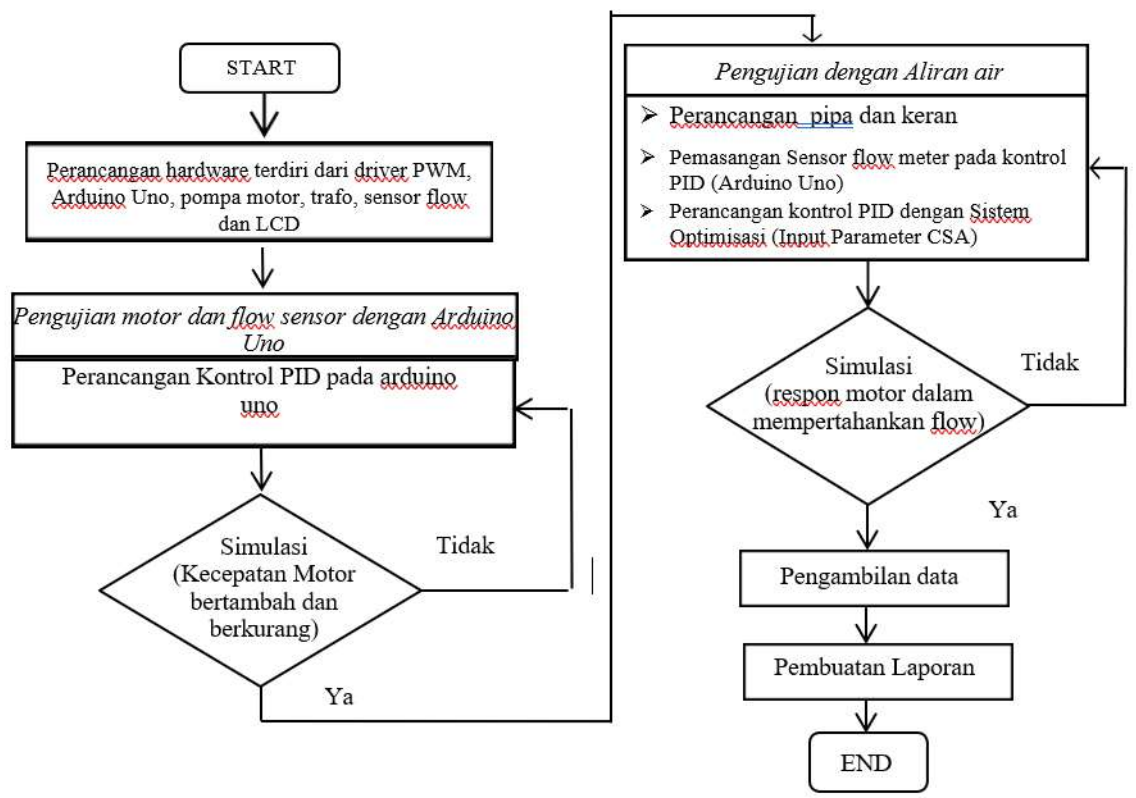

Gambar 4. Blok diagram penelitian

Dalam metode penelitian ini akan diawali dengan membangun perancangan hardware untuk pengujian motor dan flow sensor dengan arduino uno untuk melihat secara aktual respon sensor terhadap aliran air. Selanjutnya diverifikasi secara menyeluruh dengan kontrol PID yang dioptimasi dengan CSA serta pengujian respon time naik turun motor untuk mempertahankan flow dengan buka tutup keran

\subsection{Perancangan Perangkat keras}

Berdasarkan blok diagram penilitian diatas, perancangan perangkat keras terdiri dari Trafo 220/9 VAC, Dioda bridge 1n4007, kapasitor, driver motor TIP 122, arduino Uno, flow sensor, LCD dan pompa motor

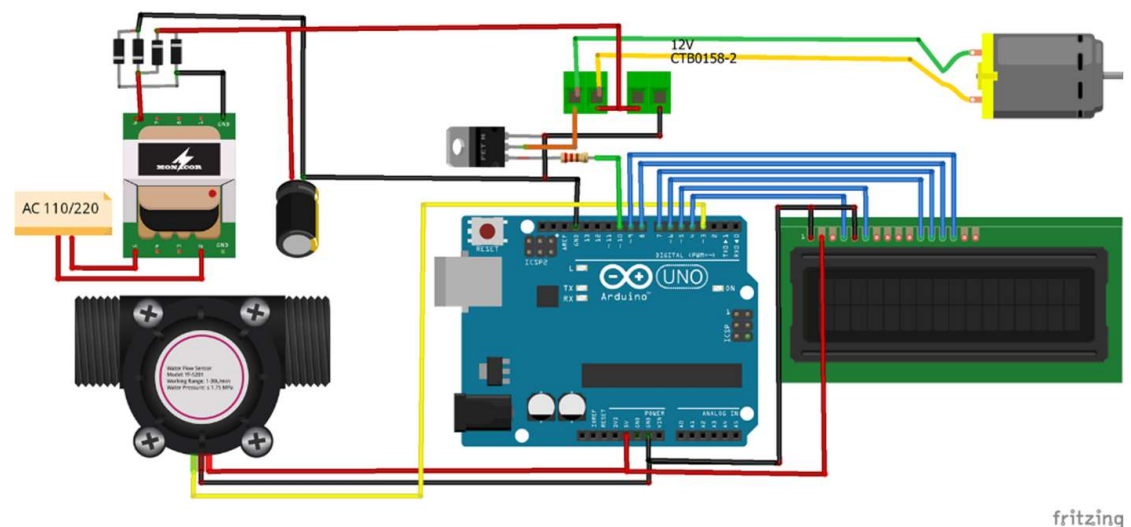

Gambar 5. Perancangan perangkat keras 
Pada plant ini digunakan Arduino Uno sebagai pusat dari pengolah data. Agar sebuah Arduino Uno dapat bekerja sebagai pengontrol, kaki-kaki pin Arduino uno dihubungkan dalam rangkaian-rangkaian eksternal. Berikut bagian-bagian pin dalam Arduino Uno

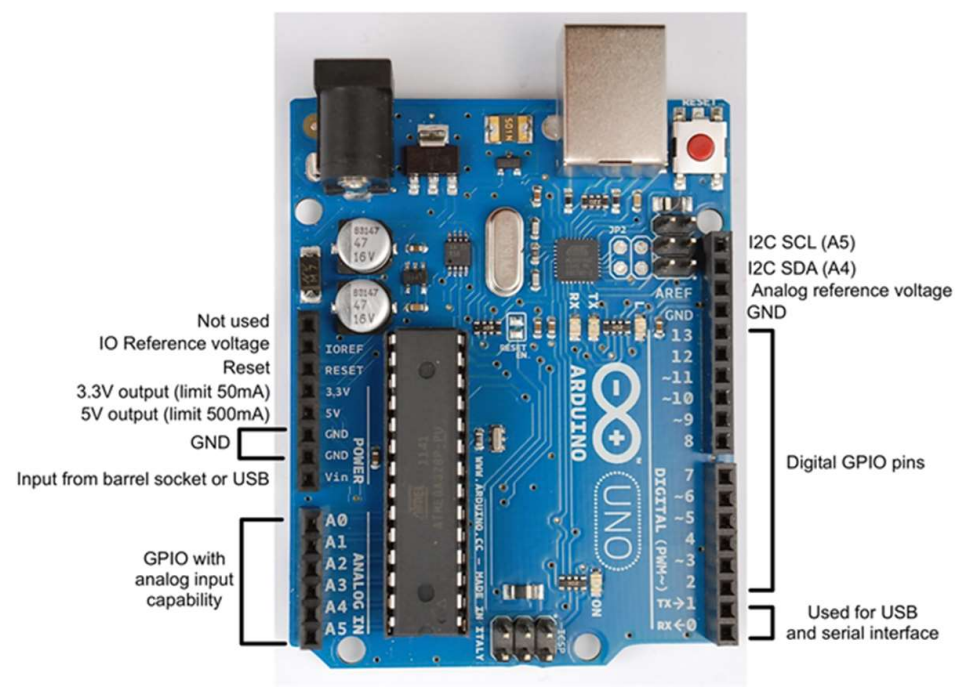

Gambar 6. Arduino Uno pinout

Dalam perancangan ini, pin yang digunakan adalah sebagai berikut

Tabel 2. Tabel Pinout yang digunakan

\begin{tabular}{|c|c|c|}
\hline \multicolumn{2}{|c|}{ Arduino Pin } \\
\hline Pin Arduino & Digunakan untuk \\
\hline GND & GND & \multicolumn{1}{|}{} \\
\hline VCC & VCC & \multirow{2}{*}{ LCD input dan outpin pin } \\
\hline 4 & RS & \\
\hline GND & RW & \\
\hline 5 & Enable & \\
\hline 6 & d4 & \\
\hline 7 & d5 & Transistor \\
\hline 8 & d6 & Flow sensor \\
\hline 9 & d7 & \\
\hline 10 & Rin & \\
\hline 3 & Signal & \\
\hline
\end{tabular}

Sebagai suplai catu daya yang sudah diturunkan digunakan transformator. Transformator (trafo) adalah suatu peralatan elektronika yang digunakan untuk menaikkan atau menurunkan tegangan listrik. Transformator terbuat dari sebuah lempengan besi berlapis yang disebut inti trafo dan 2 buah lilitan kawat pada kedua sisinya. Pada perancangan ini tegangan 220 VAC diturunkan ke 9VAC.

Lalu digunakan dioda bridge sebagai penyearah arus bolak balik. Dioda Bridge pada dasarnya merupakan susunan dari empat buah Dioda yang dirangkai dalam konfigurasi rangkaian jembatan (bridge) yang dikemas menjadi satu perangkat komponen yang berkaki empat. Dua kaki Terminal dipergunakan sebagai Input untuk tegangan/arus listrik AC (bolak balik) sedangkan dua kaki 
terminalnya lagi adalah terminal Output yaitu Terminal Output Positif $\left(^{+}\right)$dan Terminal Output Negatif (-).Konfigurasi rangkaian jembatan Bridge Diode ini dapat menghasilkan polaritas atau arah yang sama pada Output dari kedua polaritas Input yang bolak-balik. Diode Bridge yang merupakan komponen untuk penyearah gelombang penuh (full wave rectifier) ini adalah penyearah yang sering digunakan dalam rangkaian Pencatu Daya (Power Supply) karena kinerjanya yang lebih baik dengan ukuran yang lebih kecil dan juga biaya yang relatif murah

Sebagai penguat(amplifier) serta sebagai driver dan media switching digunakan transistor daya/darlington. Dalam perancangan ini digunakan transistor TIP 122 yang merupakan transistor daya NPN dengan konfigurasi darlington yang adalah sepasang transistor bipolar yang terhubung untuk memberikan keuntungan arus sangat tinggi dari arus basis rendah. Dalam transistor Darlington, emitor transistor input ditransfer ke basis transistor output dan kolektor mereka terikat bersama. Oleh karena itu, arus yang diperkuat oleh transistor input diperkuat lebih jauh oleh transistor keluaran. Karakteristiknya adalah sebagai berikut :

1. Tegangan maksimum kolektor - Emiter ( Vce ) 100 VOLT

2. Tegangan maksimum kolektor - Basis ( Vcb) 5 VOLT

3. Tegangan maksimum Emiter - Basis ( Veb ) 6 VOLT

4. Arus kolektor konstan $500 \mathrm{~mA}$

Dalam perancangan ini juga digunakan water flow sensor sebagai sensor dan media feedback untuk pengaturan kecepatan motor, water flow sensor yang digunakan memiliki spesifikasi sebagai berikut

- $\quad$ Bekerja padategangan5V DC-24VDC

- $\quad$ Arus Maksimum $15 \mathrm{~mA}$ (DC5V)

- $\quad$ Berat sensor $43 \mathrm{~g}$

- $\quad$ Tingkat Aliran rentang 1 30L / menit

- Suhu Pengoperasian $0^{\circ} \mathrm{C} \sim 80^{\circ}$

- $\quad$ Operasi kelembaban35\% 90\% RH

- $\quad$ Operasi tekanan air $<1.75 \mathrm{Mpa}$

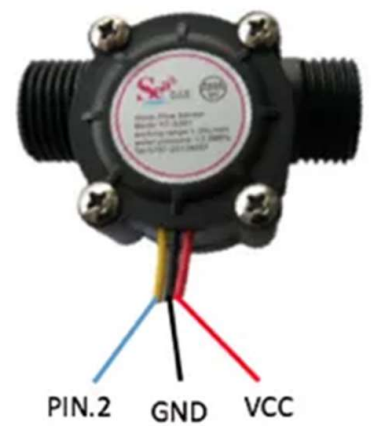

Gambar 6. Water Flow Sensor 
Pada kaki pin signal (Kuning) dihubungkan ke digital pwm ( 3) pada pin arduino uno karena signal berupa digital, untuk power positifnya (Merah) menggunakan pin VCC dihubungkan ke pin 5V arduino dan negatifnya (GND) dihubungkan ke pin GND pada arduino uno.

Untuk pompa air yang digunakan merupakan pompa air DC submersible dengan spesifikasi tegangan $12 \mathrm{VDC}$, daya $19 \mathrm{~W}$ dan mampu mengalirkan air sebesar $800 \mathrm{~L} / \mathrm{h}$

\subsection{Perancangan Perangkat lunak}

Pada perancangan perangkat lunak (software) digunakan Arduino IDE 1.8.7 sebagai media untuk menuliskan code command dan kontrol PID, sedangkan untuk optimasi Cucko Saerch Algortihm nya menggunakan matlab,

\section{HASIL DAN PEMBAHASAN}

\subsection{Pengujian water flow sensor}

Pada tahapan ini dilakukan pengujian water flow sensor terhadap aliran keluaran pompa untuk melihat respon yang dihasilkan sensor saat merasakan aliran serta melihat aliran maksimal dari keluaran pompa. Pompa disini juga sekaligus diatur kecepatannya dengan pemberian variasi tegangan PWM sehingga kita juga dapat melihat tegangan motor secara aktual. Berikut tabel hasil pengujiannya.

Tabel 3. Data hasil uji pengujian water flow sensor dengan variasi PWM

\begin{tabular}{|r|c|c|c|}
\hline No & PWM & $\begin{array}{c}\text { Output Flow } \\
\text { (RPS) }\end{array}$ & $\begin{array}{c}\text { Voltase } \\
\text { Motor }\end{array}$ \\
\hline 1 & 250 & 35 & 11,76 \\
\hline 2 & 245 & 36 & 11,53 \\
\hline 3 & 240 & 37 & 11,29 \\
\hline 4 & 235 & 38 & 11,06 \\
\hline 5 & 230 & 37 & 10,82 \\
\hline 6 & 225 & 36 & 10,59 \\
\hline 7 & 220 & 36 & 10,35 \\
\hline 8 & 215 & 36 & 10,12 \\
\hline 9 & 210 & 36 & 9,88 \\
\hline 10 & 205 & 35 & 9,65 \\
\hline 11 & 200 & 35 & 9,41 \\
\hline 12 & 195 & 34 & 9,18 \\
\hline 13 & 190 & 34 & 8,94 \\
\hline
\end{tabular}

\begin{tabular}{|c|c|c|c|}
14 & 185 & 33 & 8,71 \\
\hline 15 & 180 & 34 & 8,47 \\
\hline 16 & 175 & 32 & 8,24 \\
\hline 17 & 170 & 33 & 8,00 \\
\hline 18 & 165 & 32 & 7,76 \\
\hline 19 & 160 & 31 & 7,53 \\
\hline 20 & 155 & 31 & 7,29 \\
\hline 21 & 150 & 29 & 7,06 \\
\hline 22 & 145 & 29 & 6,82 \\
\hline 23 & 140 & 29 & 6,59 \\
\hline 24 & 135 & 29 & 6,35 \\
\hline 25 & 130 & 27 & 6,12 \\
\hline 26 & 125 & 32 & 5,88 \\
\hline 27 & 120 & 25 & 5,65 \\
\hline 28 & 115 & 25 & 5,41 \\
\hline
\end{tabular}


| Vol. 1 | No. 1 | Halaman 1 - 14

e-ISSN : 2721-320X

[Maret] [2020] JASEE

p-ISSN : 2721-3625

\begin{tabular}{|c|c|c|c|}
29 & 110 & 24 & 5,18 \\
\hline 30 & 105 & 23 & 4,94 \\
\hline 31 & 100 & 22 & 4,71 \\
\hline 32 & 95 & 20 & 4,47 \\
\hline 33 & 90 & 20 & 4,24 \\
\hline 34 & 85 & 20 & 4,00 \\
\hline 35 & 80 & 18 & 3,76 \\
\hline 36 & 75 & 16 & 3,53 \\
\hline 37 & 70 & 15 & 3,29 \\
\hline 38 & 65 & 12 & 3,06 \\
\hline 39 & 60 & 10 & 2,82 \\
\hline
\end{tabular}

\begin{tabular}{|c|c|c|c|}
40 & 55 & 9 & 2,59 \\
\hline 41 & 50 & 7 & 2,35 \\
\hline 42 & 45 & 5 & 2,12 \\
\hline 43 & 40 & 2 & 1,88 \\
\hline 44 & 35 & 1 & 1,65 \\
\hline 45 & 30 & 0 & 1,41 \\
\hline 46 & 25 & 1 & 1,18 \\
\hline 47 & 20 & 0 & 0,94 \\
\hline 48 & 15 & 6 & 0,71 \\
\hline 49 & 10 & 3 & 0,47 \\
\hline 50 & 5 & 0 & 0,24 \\
\hline
\end{tabular}

\subsection{Pengujian Response time kecepatan motor terhadap perubahan debit air}

Setelah pengujian pengujian water flow sensor dengan variasi PWM selanjutnya penguijan responses time kecepatan motor terhadap perubahan debit air dengan kontrol PID tanpa optimasi dan dengan optimasi CSA. Pada pengujian ini kita set point value (flow set) berada di 20, 23 dan 25 RPS. Berikut data hasil pengujian response time motor dengan kontrol PID dengan dan tanpa optimasi CSA
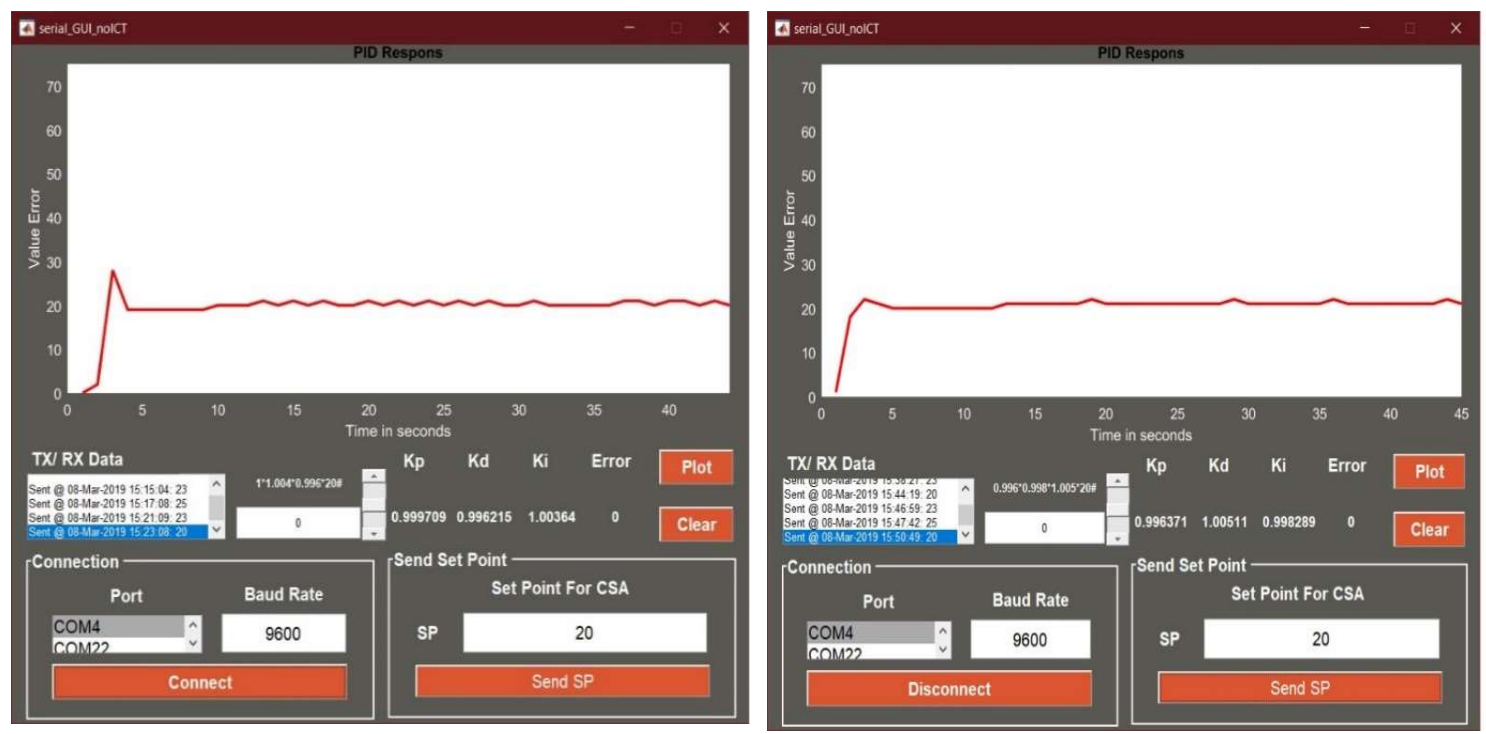

Gambar 7. Perbandingan respons time antara dengan tanpa optimasi CSA dan dengan optimasi CSA dengan setpoint 20 RPS 

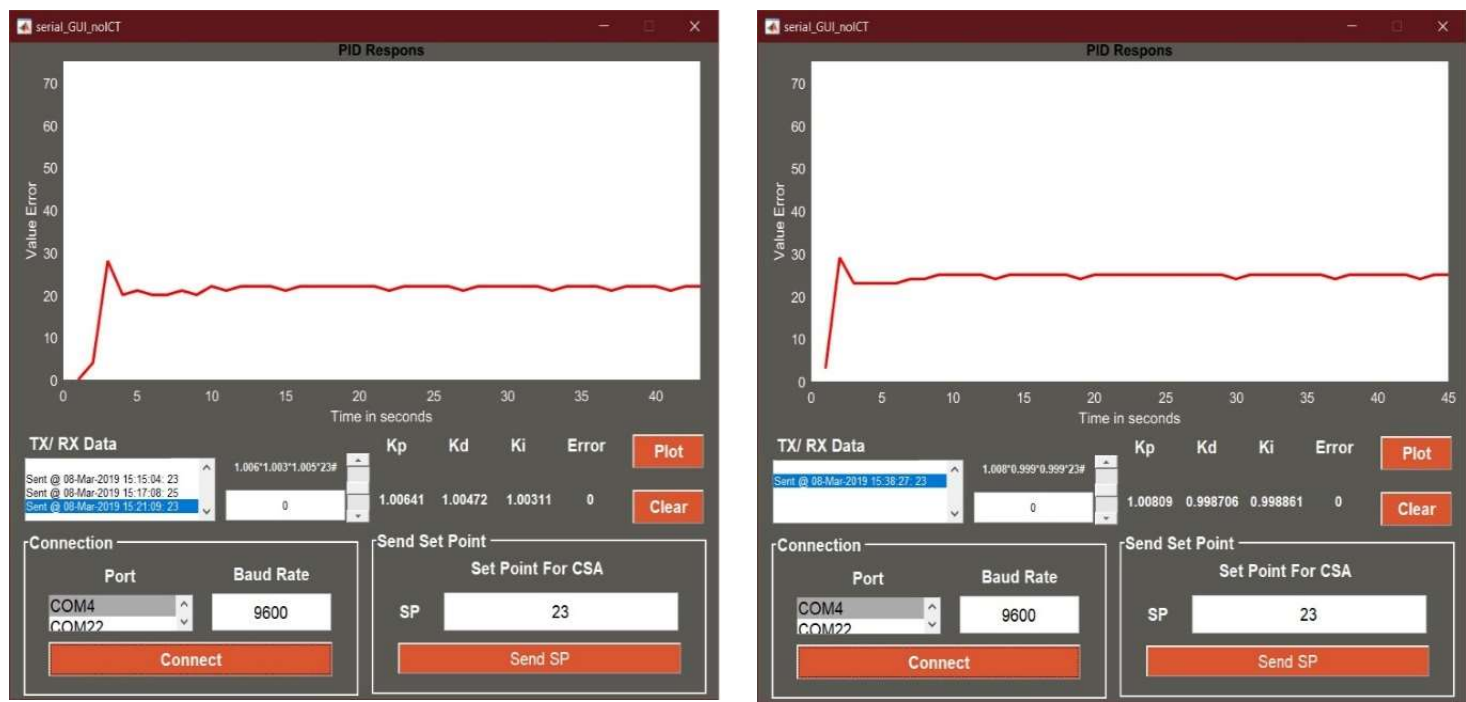

Gambar 8. Perbandingan respons time antara dengan tanpa optimasi CSA dan dengan optimasi CSA dengan setpoint 23 RPS

Dari hasil percobaan diatas di dapatkan bahwa dengan optimasi cuckoo menghasilkan respons yang sedikit lebih baik dibanding dengan tanpa optimasi cuckoo dengan pertimbangan kemampuan motor. Pada setpoint 20 RPS terlihat lebih baik karena overshoot yang dihasilkan lebh sedikit dibanding ketika menggunakan setpoint 23 RPS, sehingga pengujian selanjutnya dengan variasi pembukaan keran menggunakan setpoint 20 RPS, berikut hasil dari pengujian selanjutnya

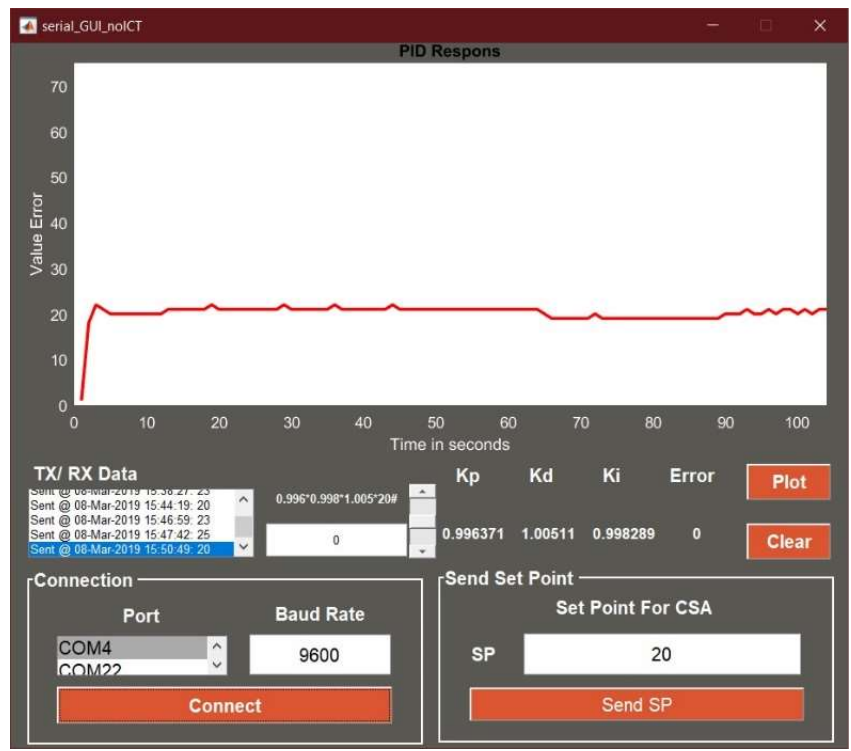

Gambar 9. Hasil respons time dengan variasi pembukaan keran dengan setpoint 20

Dalam pengujian ini pada detik ke 65 pembukaan keran mulai ditambahkan perlahan hingga penuh lalu di tutup kembali. 


\section{KESIMPULAN}

Berdasarkan pengujian yang telah dilakukan, maka dapat disimpulkan bahwa kontrol PID dengan optimasi cuckoo search alogirtma ini dapat menghasilkan peningkatan response time lebih baik dibandingkan dengan kontrol PID dengan trial error. Nilai overshoot yang minim ada pada setpoint 20 RPS dengan nilai $\mathrm{Kp}=0,996371, \mathrm{Ki}=0,99829$, dan $\mathrm{Kd}=1.00511$. Overshoot yang muncul lebih dikarenakan adanya sisa udara disekitar water flow sensor sehingga dalam pengujian perlu pengosongan udara. Hasil optimasi Aliran air masih sedikit belum bisa stabil dipertahankan karena keterbatasasn kemampuan pompa air serta pembukaan keran yang dilakukan tidak bisa dilakukan dengan buka tutup secara penuh yang juga dikarenakan kemampuan pompa motor yang terbatas. Dalam pengujian ini masih ada beberapa hal yang dapat ditingkatkan untuk kedepannya, seperti penggunaan motor pompa yang lebih bertenaga sehingga aliran yang terbaca bisa lebih besar dan variasi pengaturan dapat dilakukan dengan lebih baik atau penggunaan sensor yang memiliki sensitifitas yang baik sehingga data feedback yang dikirimkan bisa lebih konstan, realtime dan stabil seperti penggunaan pressure water sensor.

\section{UCAPAN TERIMA KASIH}

Peneliti banyak menerima bimbingan, petunjuk dan bantuan serta dorongan dari berbagai pihak baik yang bersifat moral maupun material. Pada kesempatan ini penulis menyampaikan rasa terima kasih yang sebesar-besarnya kepada, Tuhan yang Maha Esa yang memberikan rahmat dann karunianya serta kepada Bapak Gigih dan Bapakak Mukhsim selaku dosen pembiming yang telah memberi masukan untuk menyelesaikan penelitian ini.

\section{DAFTAR RUJUKAN}

[1] G. R. A. Cempaka, "Pengendalian tekanan pada sistem homogenisasi susu dengan kontroler pid berbasis arduino uno," J. Mhs. TEUB, vol. 2, no. 7, 2015.

[2] S. T. Rini Nur Hasanah, H. W. Putra, dan I. Wijono, "Perancangan Sistem Pengendalian Kecepatan Motor Pompa Air Tekanan Konstan," J. Mhs. Tek. Elektro Univ. Brawijaya, vol. 3, no. 1.

[3] M. S. Mauludin, R. Wijanarko, dan N. E. Budiyanto, "Simulasi Kontrol Pid Untuk Mengatur Putaran Motor AC," Pros. SNST Fak. Tek., vol. 1, no. 1, 2014.

[4] M. R. Djalal, D. Ajiatmo, A. Imran, dan I. Robandi, "Desain Optimal Kontroler Pid Motor Dc Menggunakan Cuckoo Search Algorithm," SENTIA 2015, vol. 7, no. $1,2015$.

[5] Q. Bai, "Analysis of particle swarm optimization algorithm," Comput. Inf. Sci., vol. 3, no. 1, hlm. 180, 2010.

[6] Y. X.S. Yang dan S. Deb, Cuckoo Search: Recent Advances and Applications, vol. 24. 2014.

[7] D. A. Silalahi, "Pengendalian Kecepatan Putar (Rpm) Motor DC dengan Metode PID Berbasis Mikrokontroller Atmega328 Menggunakan Bahasa Pemrograman Code Vision Avr," 2017.

[8] X.-S. Yang dan S. Deb, "Engineering optimisation by cuckoo search," ArXiv Prepr. ArXiv10052908, 2010.

[9] I. Maulana, "Belajar Arduino: Mengenal PWM (Pulse Width Modulation) Pada Arduino," proyekrumahan.id, 19-Jun-2016.

[10] T. Haryanto, "Analog Output pada Arduino Menggunakan PWM (Pulse Width Modulation)," CodePolitan.com. 